13,18

\title{
Электронно-дифракционное изучение структуры эпитаксиального графена, выращенного методом термодеструкции 6H- и 4H-SiC (0001) в вакууме
}

\author{
() И.С. Котоусова ${ }^{1}$, С.П. Лебедев ${ }^{1}$, А.А. Лебедев ${ }^{1,2, \text { ฯ П. П. Булат }}{ }^{2}$ \\ ${ }^{1}$ Физико-технический институт им. А.Ф. Иофрфе, \\ Санкт-Петербург, Россия \\ ${ }^{2}$ Санкт-Петербургский национальный исследовательский университет \\ информационных технологий, механики и оптики, \\ Санкт-Петербург, Россия \\ ฯ E-mail: sura.lebe@mail.ioffe.ru
}

(Поступила в Редакцию 22 января 2018 г.)

\begin{abstract}
Методом дифракции быстрых электронов на отражение (ДБЭО) проведено исследование структуры графеновых слоев, образованных на поверхности Si-грани проводящих и полуизолирующих подложек карбида кремния $6 H$ - и $4 H-\mathrm{SiC}(0001)$ путем термодесорбции атомов $\mathrm{Si}$ в высоком вакууме, в зависимости от температуры и времени сублимации атомов $\mathrm{Si}$ и способа предобработки поверхности подложек.

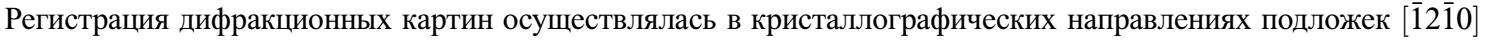
и [1100]. Установлено, что во всех проведенных экспериментах образование графеновых слоев происходит с разворотом кристаллической решетки графена на $30^{\circ}$ относительно решетки $\mathrm{SiC}$.

Статья подготовлена при финансовой поддержке Министерства образования и науки Российской Федерации (Соглашение № 14.575.21.0148, уникальный номер проекта RFMEF157517X0148).
\end{abstract}

DOI: 10.21883/FTT.2018.07.46131.016

\section{1. Введение}

Настоящая работа посвящена электронно-дифракционному исследованию структуры пленок графена, образованных на поверхности Si-грани подложек карбида кремния ( $\mathrm{SiC})$ путем термодесорбции атомов $\mathrm{Si}$ в высоком вакууме. Исследовались пленки, сформированные в разных режимах вакуумного отжига, проводимого с целью поиска оптимальных условий, пригодных для создания технологии получения пленок графена на карбиде кремния с перспективой ее применения в приборостроении полупроводниковой электроники.

\section{2. Образцы и методика измерений}

Образцами для структурного исследования служили проводящие и полуизолирующие подложки $6 \mathrm{H}$ и $4 H-\mathrm{SiC}(0001)$ производства компании CREE с механически полированной сингулярной поверхностью (Si-гранью). Синтез слоев графена осуществлялся путем термического разложения поверхности в установке сублимационной эпитаксии в вакууме по предложенной в работе [1] технологии. Условия проведения синтеза графена представлены в таблице. Предварительно перед синтезом графена осуществлялась операция по удалению царапин и других дефектов, всегда остающихся после механической полировки поверхности подложки. Для осуществления данной операции использовался метод предростового отжига подложки в танталовом тигле, обеспечивающий получение чистой атомно-гладкой поверхности подложки с морфологией из протяженных регулярных террас шириной до $500 \AA$ и высотой ступенек, равной параметру с элементарной ячейки $\mathrm{SiC}$.

Структура поверхности образцов исследовалась методом дифракции быстрых электронов на отражение (ДБЭО) с помощью электронографов ЭМР-102 (при ускоряющем напряжении $75 \mathrm{kV}$ ) и ЭМР-100 (при напряжении $50 \mathrm{kV}$ ).

\section{3. Результаты и обсуждение}

Перед проведением операции термодеструкции подложки образцов проходили электронографический контроль, показавший их высокое структурное совершенство.

Типичные электронограммы, полученные в 2-х кристаллографических направлениях поверхности $\mathrm{SiC}(0001)$ от образцов после операции термодеструкции в разных условиях отжига (таблица), представлены на рис. $1, a-e$ и рис. $2, a-e$.

На рис. 1, $a-e$ показаны электронограммы (с результатами индицирования электронограммы на рис. 1, $a$ ), полученные от поверхности отожженных образцов в азимуте $[\overline{1} 2 \overline{1} 0]$ относительно подложки $\mathrm{SiC}$; однако следует добавить, что индицирование электронограмм от кристаллов с гексагональной структурой не является однозначным. Идентичные картины, представленной в азимуте $[\overline{1} 2 \overline{1} 0]$ картине (рис. $1, a)$, возникают также при 
Параметры образцов, использовавшихся для проведения исследований

\begin{tabular}{|c|c|c|c|c|}
\hline Образец & Подложка & $\begin{array}{c}\text { Предростовой } \\
\text { отжиг }\end{array}$ & $\begin{array}{c}\text { Температура } \\
\text { роста, }{ }^{\circ} \mathrm{C}\end{array}$ & $\begin{array}{c}\text { Время } \\
\text { роста, min }\end{array}$ \\
\hline GR-15 & $\begin{array}{c}6 H-\mathrm{SiC} \\
\text { проводящая }\end{array}$ & нет & 1350 & 20 \\
\hline GR-13 & $\begin{array}{c}\text { 6H-SiC } \\
\text { проводящая }\end{array}$ & нет & 1430 & 10 \\
\hline GR-60 & $\begin{array}{c}\text { 6H-SiC } \\
\text { полуизолирующая }\end{array}$ & да & 1560 & 2 \\
\hline GR-105 & $\begin{array}{c}6 H-\mathrm{SiC} \\
\text { проводящая }\end{array}$ & да & 1500 & 30 \\
\hline GR-108 & $\begin{array}{c}4 H-\mathrm{SiC} \\
\text { полуизолирующая }\end{array}$ & да & 1570 & 15 \\
\hline
\end{tabular}

электронографировании поверхности (0001) $\mathrm{SiC}$ вдоль направлений $[2 \overline{1} \overline{1} 0]$ и $[11 \overline{2} 0]$ (при последовательном вращении образца относительно электронного пучка на $60^{\circ}$ ). В таких случаях при индицировании электронограммы происходит замена индексов отражений от плоскостей $\mathrm{SiC}(h 0 . l)$ (рис. 1,a) на $(0 k . l)$ и $(h \bar{h} . l)-$

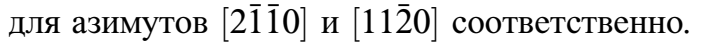

Анализ представленных на рис. $1, a-e$ электронограмм показал присутствие отражений 11 от графена в плоскости (010) обратной решетки $\mathrm{SiC}$, свидетельствуя о том,что сопрягающиеся плоскости (0001) $\mathrm{SiC}$ и (0001) графена развернуты в плоскости подложки на $30^{\circ}$, так что направления $\langle\overline{1} 2 \overline{1} 0\rangle \mathrm{SiC}$ параллельны $\langle 1 \overline{1} 00\rangle$ графена. Это находится в соответствии с эпитаксиальным соотношением между кристаллической решеткой графена и решеткой $\mathrm{SiC}(0001)$, впервые установленным благодаря использованию методов дифракции медленных электронов и Оже-спектроскопии [3] в процессе образования монослоя графита при высоковакуумном отжиге $\mathrm{SiC}$.

Рефлексы от графена 11 на картинах дифракции рис. $1, a-c$ имеют вид непрерывных вертикальных стержней, что является характерным признаком двумерной дифракции.

На электронограмме рис. 1, $a$, кроме интенсивных отражений от графена, наблюдаются также стержнеобразные рефлексы, соответствующие интенсивным отражениям (10.l) $\mathrm{SiC}$ и слабоинтенсивными отражениями (20.l)SiC с сопутствующими им слабоинтенсивными рефлексами-сателлитами, которые вкупе отвечают картине дифракции от реконструкции поверхности $\mathrm{SiC}$ $6(\sqrt{ } 3 \times \sqrt{ } 3) R 30$ (сокращенно $6 \sqrt{ } 3$ ) [4,5]. Таким образом, электронограммы на рис. $1, a$, а также на рис. $1, b, c$ (с менее богато представленными рефлексами от реконструкции) являются суперпозицией дифракционных картин от графена и реконструкции $6 \sqrt{ } 3$, или буферного слоя графена. Было проведено сопоставление относительной интенсивности отражений на электронограммах рис. $1, a-c$ с относительной интенсивностью отражений на картине дифракции от чистой реконструкции
$6 \sqrt{ } 3$, полученной методом RHEED также в направлении $[\overline{1} 2 \overline{1} 0]_{\mathrm{SiC}}[5]$. В результате было установлено, что в образце GR-15 заметную площадь занимает буферный слой (рис. $1 a$ ), в образце GR-13 - в основном представлен графен, а электронограмма образца ПК-60 (рис. 1,c) имеет больше сходства с картиной дифракции от GR-15, чем от GR-13. Следует отметить, что условия отжига образцов GR-15 и GR-60 весьма разнятся: GR-15 не подвергался предростовому отжигу перед операцией термодеструкции, в отличие от GR-60 (таблица); однако, уже 2-х минутный отжиг с поышением температуры отжига с $1350^{\circ} \mathrm{C}$ (с длительностью отжига $20 \mathrm{~min}$ ) до $1560^{\circ} \mathrm{C}$ показал близкие картины дифракции от поверхности образцов GR-15 и GR-60.

Электронограмма на рис. $1, d$ получена от образца GR-105, подвергнутого отжигу при $1500^{\circ} \mathrm{C}$ в течение 30 min с применением, как и GR-60, предростового отжига. На электронограмме уже отсутствуют отражения от буферного слоя; стержнеобразные рефлексы (11) от графена не являются непрерывными стержнями, а состоят из коротких тяжей. Рефлексы-тяжи вместе с дифракционными максимумами, наблюдаемыми на центральном рефлексе (001) электронограммы, составляют правильную сетку сечения (1피) обратной решетки графита, и в результате электронограмма приобретает вид, характерный для картины дифракции быстрых электронов на достаточно протяженном пакете единичных слоев (не менее 3-х) графена, с упаковкой слоев по Берналу.

Электронограмма на рис. 1,e, зарегистрированная от поверхности образца GR-108, также демонстрирует нарушение непрерывного характера стержнеобразных рефлексов от графена, которое, однако, не приводит к образованию узловой сетки графита, как на электронограмме рис. $1, d$. В этом случае прерывистый характер рефлексов 11 обусловлен формированием картины электронной дифракции от поверхности графена при съемке в азимуте структуры $\mathrm{SiC}$ [1210], что будет продемонстрировано после представления и анализа электроно- 

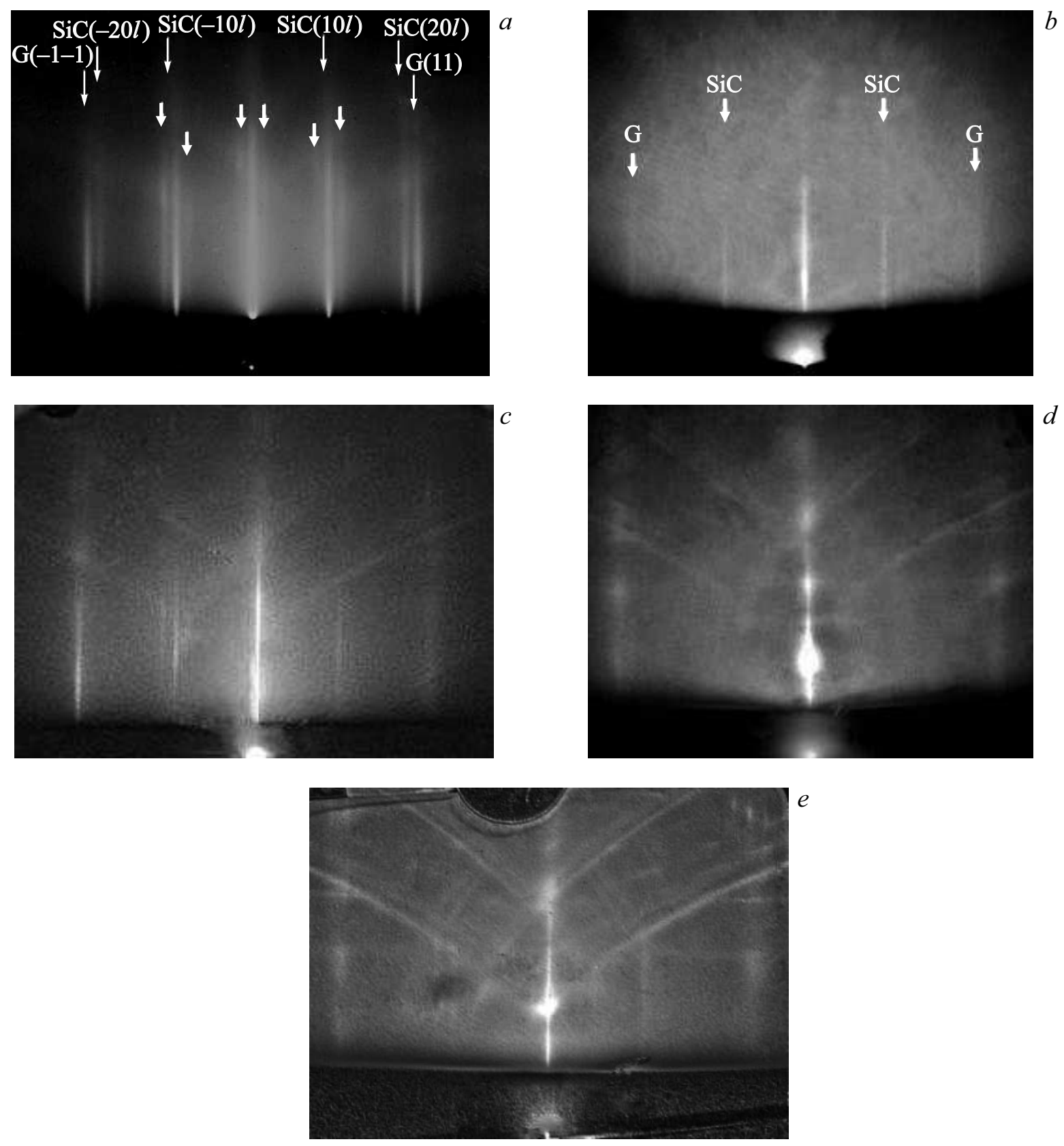

Pис. 1. Электронограммы в азимуте $[\overline{1} 2 \overline{1} 0]_{\mathrm{SiC}}$ с углом падения электронного пучка, не превышающим $1.5^{\circ}$, от поверхности $6 H$-SiC после термодеструкции: $(a)-$ при $T=1350^{\circ} \mathrm{C} 20 \mathrm{~min}(\mathrm{GR}-15),(b)-$ при $T=1430^{\circ} \mathrm{C} 10 \mathrm{~min}(\mathrm{GR}-13)$; $(c)-$ при $T=1560^{\circ} \mathrm{C} 2 \min (\mathrm{GR}-60),(d)$ - при $T=1570^{\circ} \mathrm{C} 30 \min (\mathrm{GR}-105),(e)-$ при $T=1570^{\circ} \mathrm{C} 15 \min (\mathrm{GR}-108)$. На электронограммах c маркировкой: короткие стрелки без обозначений указывают на рефлексы-сателлиты, отвечающие реконструкции $\mathrm{SiC}$ $6(\sqrt{ } 3 \times \sqrt{ } 3) R 30$, т.е. буферному слою графена. Электронограммы $a)$ и $b$ ) снимались на электронографе ЭМР-102, а $c-e)-$ на электронографе ЭМР-100.

грамм с регистрацией в азимуте [1ํㅣㅇㅣ и сопоставления полученных результатов в обоих направлениях.

На рис. 2, $a-e$ приведены электронограммы от поверхности образцов в азимуте [1100] относительно подложки $\mathrm{SiC}$ с результатами индицирования их на рис. $2, a$. Аналогичные картины можно наблюдать для азиму-

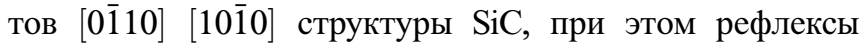
(11.l) $\mathrm{SiC}$ (как на электронограмме рис. 2,a) заменяются на $(2 \overline{1} . l))$ и $(\overline{1} 2 . l)$ на картинах с азимутами [01ㅣㄹ и и $[10 \overline{1} 0]$ соответственно.

В соответствии с эпитаксиальным соотношением между кристаллической решеткой графена и решеткой подложки $\mathrm{SiC}(0001)$ представленные на рис. 2, $a-e$ электронограммы демонстрируют присутствие отражений 10 от графена в плоскости (110) обратной решетки $\mathrm{SiC}$. В азимуте [11̄00] $\mathrm{SiC}$ рефлексы 10 от графена 

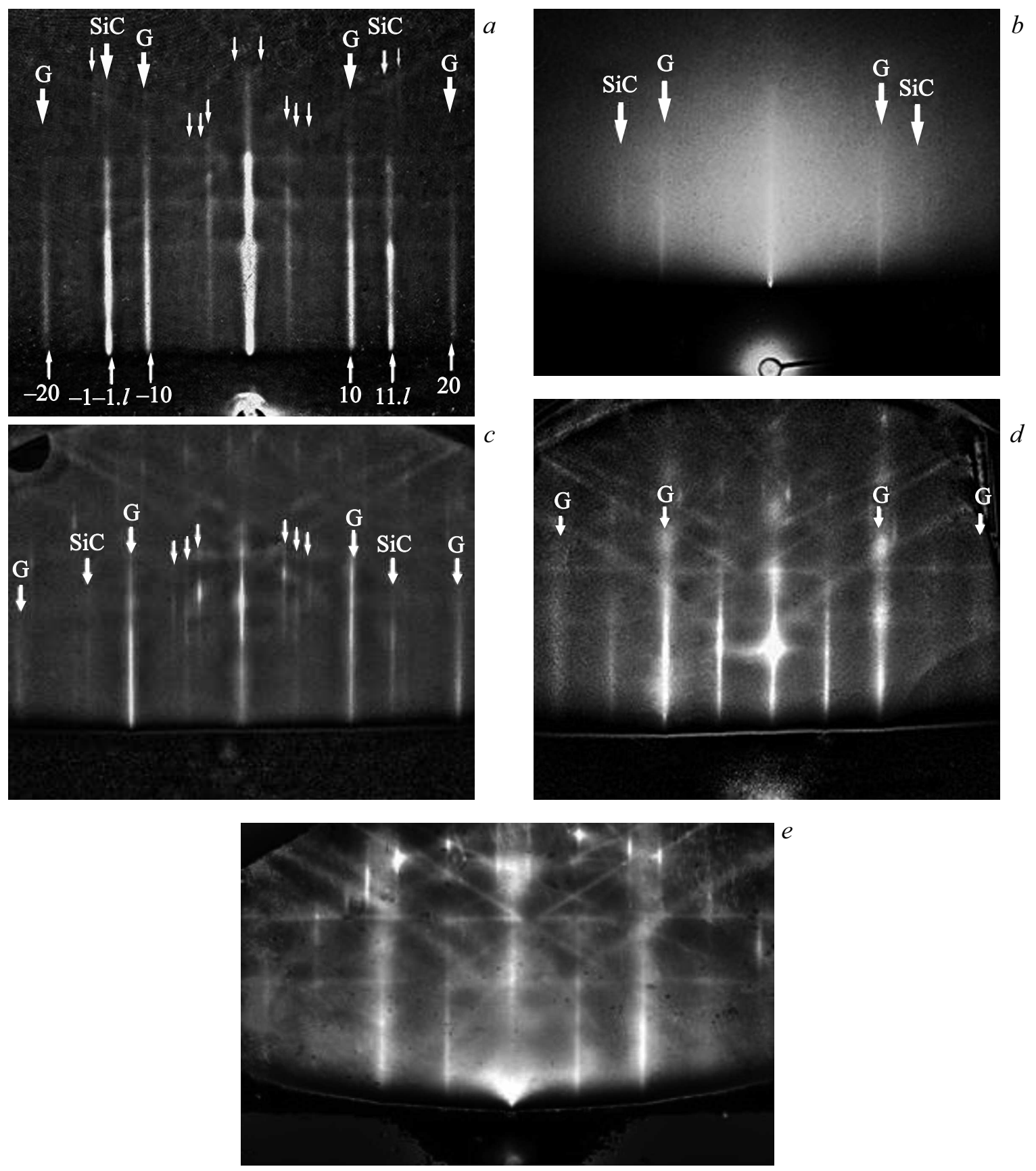

Pис. 2. Электронограммы в азимуте с $[1 \overline{1} 00]_{\mathrm{SiC}}$ с углом падения электронного пучка, не превышающим $2^{\circ}$, от поверхности $6 H$-SiC после термодеструкции: $(a)-$ при $T=1350^{\circ} \mathrm{C} 20 \mathrm{~min}(\mathrm{GR}-15),(b)-$ при $T=1430^{\circ} \mathrm{C} 10 \mathrm{~min}(\mathrm{GR}-13)$; $(c)-$ при $T=1560^{\circ} \mathrm{C} 2 \min (\mathrm{GR}-60),(d)$ - при $T=1570^{\circ} \mathrm{C} 30 \mathrm{~min}(\mathrm{GR}-105),(e)-$ при $T=1570^{\circ} \mathrm{C} 15 \min (\mathrm{GR}-108)$. На электронограммах с маркировкой: стрелки без обозначений указывают на рефлексы-сателлиты, отвечающие реконструкции $\mathrm{SiC} 6(\sqrt{ } 3 \times \sqrt{ } 3) R 30$, т. е. буферному слою графена. Электронограммы $a$ ) и $b$ ) снимались на электронографе ЭМР-102, а $c-e)-$ на электронографе ЭМР-100

на всех картинах дифракции от всех исследованных образцов (рис. 2,a-e) имеют виднепрерывных вертикальных стержней. Кроме отражений от графена на электронограммах образцов GR-15 и GR-13 наблюдаются отражения от буферного слоя - многочисленные на дифракционной картине от GR-15 (рис. 2,a) и в присутствии только двух укороченных рефлексов-тяжей, соответствующих отражению $\mathrm{SiC}$ типа $(11 . l)$ - в случае образца GR-13 (рис. 2,b).

Таким образом на электронограммах рис. $2, a, b$, как и на рис. $1, a, b$ в азимуте [121010], устанволено неполное зарастание буферного слоя графеном на образцах GR-15 и GR-13, прошедших темодеструкцию без предростого отжига, но с более полным покрытием 
графеном буферного слоя на образце GR-13. Привлекая к полученному реузльтату установленные методом ожеспектроскопии данные о толщине углеродной пленки на образце, синтезированной при $1350^{\circ} \mathrm{C}$ в течение $20 \mathrm{~min}$, равной 4-5 слоям моноатомных слоев графита [1], можно сделать вывод о неравномерном росте графена на образцах, выращенных без применения предростого отжига перед операцией термодеструкции.

Электронограммы от образцов (рис. 2,c-f) с предростовым ростом были получены с помощью электронографа ЭМР-100 при ускоряющем напряжении $50 \mathrm{kV}$ (в отличие от картин дифракции на рис. $2, a, b$, зарегистрированных с помощью ЭМР-102 при $75 \mathrm{kV}$ ). Электронограммы на рис. $2, c-e$ состоят не только из нулевой зоны Лауэ, как рис. $2, a, b$, но и дробной лауэ-зоны. Дробная лауэ-зона на рис. 2, $c-e$ представлена дугообразно расположенными короткими рефлексами-тяжами, отвечающими отражениям от буферного слоя, находящегося под графеном. Подобная картина электронной дифракции наблюдалась в работе [6] от образцов, покрытых однослойным графеном.

Проведенная дополнительная съемка образцов без предростого отжига с помощью ЭМР-100 не выявила появления дробной лауэ-зоны на электронограммах.

В нулевой лауэ-зоне рис. 2, $c-e$ наиболее интенсивными являются стержнеобразные рефлексы от графена 10, разделенные между собой штрихами посередине, создавая картину, напоминающую картину на отражение от реконструкции $(2 \times 2)$, что является доказательством атомной гладкости поверхности в направлении, в котором зарегистрирована дифракционная картина $[7,8]$.

На картине дифракции от GR-60 (рис. 2,c) (температура отжига: $1560^{\circ} \mathrm{C}$, время отжига: $2 \mathrm{~min}$ ) присутствуют как интенсивные отражения 10 от графена, так и отражения от буферного слоя. Отражения от буферного слоя наблюдаются в нулевой зоне Лауэ в форме слабоинтенсивных протяженных стержнеобразных рефлексов, а в дробной зоне Лауэ в виде коротких тяжей. Нулевая зона Лауэ на электронограмме рис. 2, $c$, как и на рис. 1,c, демонстрирует неполное зарастание буферного слоя графеном в образце GR-60.

На электронограммах (рис. 2,d) от образца GR-105, образованного при $1500^{\circ} \mathrm{C}$ в течение $30 \mathrm{~min}$, на стержнеобразных рефлексах графена 10 и на центральном рефлексе наблюдается присутствие дифракционных максимумов, отвечающих узловой сетке графита (010), что находится в согласии с наблюдаемой в азимуте $[\overline{1} 2 \overline{1} 0]_{\mathrm{SiC}}$ картиной дифракции (рис. $1, d$ ) и свидетельствует об упорядоченном расположении графеновых слоев в образце GR-105.

Подобного упорядочения не происходит в процессе термодеструкции образца GR-108 при температуре $1570^{\circ} \mathrm{C}$ в течение $15 \mathrm{~min}$ (рис. 2, e), и рефлексы 10 от графена на электронограммах, как упоминалось выше, имеют вид непрерывных тонких стержней, что характерно для дифракции от гладкой поверхности террас, когда направленность террас совпадает с азимутом съемки монокристаллического образца. С другой стороны, рефлексы 11 от графена на образце GR-108, имеющие прерывистый и несколько размытый характер, которые наблюдаются в направлении $[\overline{1} 2 \overline{1} 0]_{\mathrm{SiC}}$ (рис. 1,e), зарегистрированы от участков малого размера террасы, под углом в $30^{\circ}$ (либо $90^{\circ}$ ) к направленности террас, что приводит к уширению стержнеобразного рефлекса.

Прерывание рефлексов 11 (рис. 1,e), может быть вызвано изменением морфологии краев террас вдоль эшелона ступеней на определенной стадии сублимации атомов $\mathrm{Si}$, что было установлено методами АСМ и СТМ при термическом разложении $\mathrm{Si}$-грани карбида кремния в вакууме в температурном интервале $1400-1600^{\circ} \mathrm{C}$ многими исследователями и впервые опубликовано в [9]. Рельефная поверхность в свою очередь влияет на формирование картины электронной дифракции: стержнеобразные рефлексы приобретают вид коротких прерывистых тяжей.

\section{4. Заключение}

Проведенное электронографическое исследование структуры синтезированных слоев на сингулярной поверхности проводящих подложек $6 H$ - $\mathrm{SiC}(0001)$ методом термического разложения в вакууме в температурном интервале $1350-1430^{\circ} \mathrm{C}$ показало, что при данных температурах наблюдается неравномерный рост эпитаксиального графена с неполным зарастанием буферного слоя на подложке графеном.

Исследования, проведенные на образце с применением предростового отжига перед операцией термодеструкции сингулярной поверхности проводящей подложки $6 H-\mathrm{SiC}(0001)$, позволили установить, что при температуре термодеструкции $1500^{\circ} \mathrm{C}$ в течение $30 \mathrm{~min}$ происходит полное зарастание буферного слоя эпитаксиальным графеном с упорядоченным расположением не менее 3-х графеновых слоев с упаковкой АВ по Берналу.

Установлено, что повышение температуры термодеструкции до $1570^{\circ} \mathrm{C}$ и сокращение времени отжига до $15 \mathrm{~min}$ поверхности полуизолирующей подложки $4 H-\mathrm{SiC}$ (с предварительной предростовой обработкой), приводит к покрытию буферного слоя эпитаксиальным графеном. Процесс синтеза графена в данных условиях происходит, по-видимому, с изменением морфологии ступеней и приводит к появлению рельефа на краях террас, несмотря на первоначально атомно гладкую поверхность подложки.

Во всех проведенных экспериментах образование графеновых слоев происходит с разворотом кристаллической решетки графена на $30^{\circ}$ относительно решетки $\mathrm{SiC}$.

Авторы выражают глубокую благодарность сотрудникам кафедры аналитической химии Санкт-Петербургского государственного технологического института В.П. Рубцу и В.В. Антипову за предоставленную воз- 
можность проведения электронографических работ на электронографе ЭМР-100.

\section{Список литературы}

[1] А.А. Лебедев, И.С. Котоусова, А.А. Лаврентьев, С.П. Лебедев, И.В. Макаренко, В.Н. Петров, А.Н. Титков. ФТТ, 51, 783 (2009).

[2] S.P. Lebedev, V.N. Petrov, I.S. Kotousova, A.A. Lavrent'ev, P.A. Dement'ev, A.A. Lebedev, A.N. Titkov. Mater. Sci. Forum 679, 437 (2011).

[3] A.J. Van Bommel, J.E. Crombeen, A.Van Tooren. Surf. Sci. 48, 463 (1975).

[4] X.N. Xie, H.Q. Wang, A.T.S. Wee, K.P. Loh. Surf. Sci. 478, 57 (2001).

[5] Hoh Hui YIng. Diamond-graphene surface and interfacial adsorption studies. Diss (2010).

[6] C. Wang, H. Nakahara, Y. Saito. E-J. Surf. Sci. Nanotechnology 15, 13 (2017).

[7] Г.Э. Цырлин, В.Н. Петров, Н.К. Поляков, С.А. Масалов, А.О. Голубок, Д.В. Денисов, В.М. Устинов. ФТП 43, 1158 (1999).

[8] Т.В. Малин, А.М. Гилинский, В.Г. Мансуров, Д.Ю. Протасов, А.С. Кожухов, Е.Б. Якимов, К.С. Журавлев. ФТП 49, 1329 (2015).

[9] M.L. Bolen, S.E. Harrison, L.B. Biedermann, M.A. Capano. Phys. Rev. B 80, 115433 (2009).

Редактор К.В. Емщев 